\title{
Is Mother's Education or Household Poverty a Better Predictor for Girl's School Dropout? Evidence from Aggregated Community Effects in Rural India
}

\author{
Rachana Patel $(\mathbb{D}$, Ajay K Singh, Murari Chandra, Tina Khanna, and Sunil Mehra \\ MAMTA Health Institute for Mother and Child, New Delhi 110048, India \\ Correspondence should be addressed to Rachana Patel; contact.rachi@gmail.com
}

Received 5 March 2018; Accepted 12 July 2018; Published 16 September 2018

Academic Editor: Jose C. Nunez

Copyright (c) 2018 Rachana Patel et al. This is an open access article distributed under the Creative Commons Attribution License, which permits unrestricted use, distribution, and reproduction in any medium, provided the original work is properly cited.

\begin{abstract}
Neighbourhoods and families are key social institutions instilled with development of early life course of adolescents. Limited research in India has examined exposure to community along with socioeconomic conditions for school-dropouts of girls. Multidimensional benefits of female education are increasingly recognized in recent years; hence, it becomes imperative to study the community components of school discontinuation particularly in rural area. This study aims to analyse effect of mother's education, community poverty, and gender equitable attitudes associated with a girl's school dropout. This study uses baseline survey data from an intervention program from poor-performing districts of India. Collinearity among individual predictors validated by variance inflation factor proceeded step-wise binary-logistic regression. Result suggests that communities with high concentrations of poverty and mother illiteracy are disadvantages with low gender perception and high levels of dropouts. Result suggests that girls living in poor communities are three times more likely to dropout and $70 \%$ more if belonged to communities with lower mother literacy. Girls who scored low on Gender Equitable Scale had less probability to dropout. The study concludes that girls from poor communities with low levels of mother literacy and non-egalitarian gender attitudes are at higher risk of school dropout.
\end{abstract}

\section{Introduction}

Neighbourhoods and families are fundamental social institutions embedded with advantages and disadvantages for development over teenage years. School attainment is one of the elementary human rights of adolescents that describe the pattern of crucial progress for future generation. In the last decade, an improvement in a girl's enrolment and education has seen tremendous shifts in India largely due to the Right to Education (RTE) Act (2010) and concerted government efforts. According to the District Information System for Education (DISE) data, about 65 million girls were enrolled in school in 2010-11, whereas this was only 40 million in 1990-91. About $33 \%$ of girls dropped out before completing elementary education as against 39\% boys in 2013-14 [1]. India has made huge strides in increasing access to schooling with net enrolment now having reached $70 \%$ at upper primary level (Grade 6 to Grade 8) in 2013-14, due to policy intervention
RTE act in the past decade [2]. However, research report showed a marked difference in school dropout among girls as compared to boys leading to low education among women. High school enrolment rate for girls in the age group 15-18 years was lower (42.3\%) compared to boys (52.7\%) [3].

The states of Rajasthan and Madhya Pradesh are ranked consistently low and remain below the national average on both the Human and Gender Development Indices [4]. Ample studies highlighted individual- and household-level reasons for girls' nonattendance and dropout that included gender discrimination by parents; undervaluing of girls' education; burden of household chores and sibling care; onset of menstrual cycle; distance from home; household poverty; physical safety of girls; and the practice of child marriage $[3,5]$. Discrimination and low education levels exist, especially among female in rural areas who have dropped out of school; as a result, women are more likely than men to be unemployed or engaged in vulnerable work [6]. A very recent 
study in rural India illustrated the role of economic factors including household poverty and gender/social norms (child marriage; value of girls' education) which were the factors associated with increased odds of school dropout and absenteeism among adolescent girls [7].

Studies in other developing countries found that parent's education is often significantly associated with whether a child drops out of school. Parents with low levels of education are more likely to have children who do not attend school or the children more likely to dropout [8-10]. Other evidences suggest that if mother is educated up to secondary, the likelihood of school retention increases about three times, relative to those had no education $[11,12]$.

Apart from individual characteristics, community behaviour and neighbourhoods are important social context for young adolescents particularly for girls because they provide access to resources, opportunities, and interactions that influence development $[13,14]$. Research from previous studies found the association between neighbourhood socioeconomic status and children's development. People living in more underprivileged communities are poorer in terms of income, education, health, and other socialdevelopment indicators [15-17]. Community-privileged circumstances are favourably associated with adolescents' educational attainment [18-22]. Conversely, surroundings' disadvantage has an intergenerational effect on adolescents' life chances, for example, individuals belonging to poor community and who are unemployed place their children at risk for social and behavioural problems [14, 23].

Girls living in disorderly neighbourhoods and norms experience deviant behaviour and possess negative attitudes towards education. A few studies have stressed the importance of combining parental contribution at the household level for school retention among adolescent girls [24-26]. However, limited research in India has examined exposure to community socioeconomic conditions for school dropouts of girls.

This study aims to analyse effect of mothers' education, community poverty, and gender equitable attitudes related to girls' school dropout. Further, the study assesses whether female community illiteracy or community poverty is a better predictor for early dropout of girls. The underlying assumption is girls who live among higher literate women are likely to have a lower probability of discontinuing school than those living in communities with lower illiterate women. Additionally, girls living in poor concentrated community are at higher risk of dropout from schools.

\section{Method}

2.1. Study Design. The current study is the baseline survey from an intervention program aimed at increasing the age at marriage and delaying first pregnancy through improved self-efficacy and gender transformative approach which was conducted in four poor performing selected districts of states Rajasthan and Madhya Pradesh, where early marriage among girls was highest (55-60\%) and lower educational attainment than the national estimates [27]. A three-stage sampling design was implemented in selecting six blocks across the study districts and further from each block, 10 villages were selected using Probability Proportion to Size (PPS). A complete house listing was done, and target respondents were selected from household using systematic random sampling. A structured tool was used for the survey to elicit key information from young girls related to educational aspirations (family and community), decisionmaking attitudes; and perceptions towards importance of girls' education and gender norms.

2.2. Study Population and Procedures. Households having at least one eligible respondent qualified to form the sampling frame of eligible households. Girls from corresponding household who fulfilled the criteria (age 14-18 year) were randomly recruited for this study. In each selected household, only one female respondent was selected for the interview to reduce the biasedness in the result. The final sample number for this cross-sectional survey was 1446 adolescent girls. The data were collected through a survey questionnaire by trained field investigators taking average time of 25-30 minutes in completing the interview. Since girls aged 14-18 years are the most vulnerable population in research, it was ensured to minimize all possible risks to the participants during the survey. Ethics review was obtained from the Institutional Review Board (IRB). Every effort was made to ensure protection and confidentiality and to reduce any potential adverse consequence to the participants. Oral consent of parents was sought and assent of minors were taken prior to the survey. The questionnaires did not request the name or other identifying variables, to ensure the anonymity of data for research purpose only. Participants did not receive any material compensation.

A structured tool was used for the survey to get the individual's sociodemographic information on age, sex, ethnical group, years of education, type of family, primary occupation of family, and parent's level of education. The survey also captured girls' educational aspirations and decision making, attitudes and perceptions towards importance of girls' education, gender norms, and decision making in matters related with marriage.

2.3. Ethical Declaration. All data collection was conducted following informed written consent from parents, health care providers, young men, and women. In the case of minors, their assent was taken along with the informed consent of their parents. Ethical permission was obtained from the Institutional Review Board for conducting research.

\subsection{Study Variables}

2.4.1. Outcome Variable. School dropout was defined as girls ever been to school but currently not in school in the study population. The school dropout status was the outcome variable for the causal model in our study.

\subsubsection{Independent Variable}

(1) Individual and Household Factors. It was found in the literature review that girls' educational outcome is related to 
a range of factors such as socioeconomic status and household and community factors which consequently result in dropout among girls in general. Socioeconomic factors considered in this paper are their current age, number of siblings, ethnic group (caste), economic status, and marital status. Women belonging to lower caste are benefitted less from higher education than other advantageous in community [28]. Hence, ethnical communities were grouped as scheduled caste (SC), scheduled tribe (ST), and other castes. Economic status was measured by household having below poverty line (BPL) card based on mainly per capital income and other parameters provided by Government of India which is an economic standard used by government to identify individuals with economic disadvantage. Marital status was categorized as never married, currently married, and married but Gauna not performed (Gauna, a traditional custom widely practiced in rural India where a couple is culturally sanctioned to cohabitate after marriage). Female-headed households face greater financial distress in general which may impact differently on children's academic achievement. In the view of that, household factors were considered such as parent's education, main occupation of family, and the decision-makers on their education [5, 29-31]. Parents education combined both father's and mother's education and categorized as both illiterate, any educated, and both educated. Some of the studies have documented that family and especially male members in partiarchial society restrict and limit the mobility and sexuality of women particularly to continue school after attaining puberty $[32,33]$. Also, occupation of the main earner in family is categorized as farmer, daily wage worker, or irregular worker and regular job in formal sector. Family situation directly and indirectly influence the child's education, aspiration, and value [34-36].

(2) Gender Perception Index. Children adopt a gender identity early in life from their family later from the community and develop gender-role preferences accordingly. Evidences supported that parental preferences for their wellbeing are gender biased and their own future prospects encourage them to keep the son in school and better opportunity compared to female $[24,36]$. Hence, gender perception of girls was measured in our study through Gender Equitable Men Scale (GEMS). Similar gender attitude scale was used in other studies for to reduce gender inequality among young adolescent in school [37].

This study adopted the measure of the GEM scale developed by Pulerwitz and Barker [38]. The scale consisted of 35 statements which covered broad domain on gender norms, education, reproductive rights, autonomy and empowerment, family planning, and so on . Three degrees of perceived attitude was coded on the scale as 0 to 2 as disagree to agree based on their equitable direction. Principle component analysis (PCA) and factor loading were performed to find out the most important variables with highest variability explained (eigenvalues) in particular factor created. The selection of factors was based on the Eigen value to be greater than 2 and factor loading on the vertical arm of the scree plot $[39,40]$. The retained 21 items on the GEM Scale combine two factors into one overall scale. Further, the predicted scores on the scale were distributed in three equal fragments assigning as low, moderate, and high gender equitable attitudes. Given the two factors easily exceeded the minimum standard of reliability (Cronbach's alpha $=0.60$ ), both were deemed reliable [41]. The internal consistency reliability of the overall scale was 0.81 (Appendix: Table 4).

(3) Community Factors. The benefit of community educational attainment, particularly among females, is reflected in changes in household behaviour and education attainment of girl. With this background, the mother literacy rate at village level was one of the explanatory variables included in this study [9]. Community development status is inclusively associated with other social and cultural behaviour through diffusion process; hence, the average age at marriage in the villages, proportion of population of socially deprived ethnic group (SC and ST) in each village, and population proportion below the poverty line in villages were considered as community-level predictors for school dropout in this study [11].

2.5. Statistical Analysis. Descriptive analysis and Pearson's chi-squared test were performed to see the association between dependent and independent confounders while binary logistic analysis was used to investigate the effect of predictors on the adolescent girls' school dropouts living in villages. Before performing causal model, collinearity among the individual predictors was checked for the binary logistic regression analysis through variance inflation factor (VIF), and value above 2.5 may be a cause for concern in weaker model [42].

The response variable is dichotomous and denoted by $Y_{i}, i=1,2, \ldots, n$ which is the Bernoulli random variable with two possible values, $Y_{i}=1$ with probability of dropout $P_{i}=P\left(Y_{i}=1 / X_{i}\right)$ and $Y_{i}=0$ with probability of not dropout from school $\left(1-P_{i}\right)=1-P\left(Y_{i}=1 / X_{i}\right)$. The expression $P_{i}$ in logistic regression model can be expressed in the form of

$$
P_{i}=P\left(Y_{i}=\frac{1}{X_{i}}\right)=\frac{e^{X i \beta}}{1+e^{X i \beta}}, \quad i=1,2, \ldots, n,
$$

where $P\left(Y_{i}=1 / X_{i}\right)$ is the probability of $i$ th adolescent girl out from school given her individual and community characteristics $X_{i}$, and $\beta=\left(\beta_{0}, \beta_{1}, \ldots \beta_{k}\right)$ are the model parameters to be estimated. The transformed logit model is given by the following:

$$
\begin{aligned}
\log \left(\frac{P_{i}}{1-P_{i}}\right)=\operatorname{logit}\left(P_{i}\right)=\sum_{n=1}^{\infty} \beta_{i} X_{i j}, \\
\quad i=1,2, \ldots, n, j=1,2, \ldots, K .
\end{aligned}
$$

\section{Results}

3.1. Sample Features. About half of the respondents belonged to the BPL group, one-fifth belonged to SC, and one-third 
belonged to ST. Most of their family practiced agriculture (48\%) for their livelihood followed by daily wage work (45\%). It was found that about 40 percent adolescent girls discontinued school at the time of the survey in the study area. Of them, three-fourth could not reach beyond standard 8th standard and universally dropped out from school after standard 10th. Of the total adolescents interviewed, about a fourth (26\%) of the respondents were married, and mean age at marriage was 14.5 years in each village. At the survey point, $40 \%$ girls were not in school, and among the dropped out, more than $70 \%$ did not study beyond 8th standard. Decision on girls' education was mainly taken by father (55\%) in family. Around $42 \%$ of adolescent girls had moderate to low gender perception in the study sample. Almost one-third of respondents' parents had no education (Table 1).

3.2. Unadjusted Correlates of School Dropout. We used Pearson chi-squared test and $t$-test for community-level variables to see their association with school dropout. The results indicate that almost all the selected individual- and family-level variables were highly associated with current school status of adolescent girls $\left(\chi^{2}, p<0.001\right)$ except for number of siblings and caste which showed weaker relationship $\left(\chi^{2}, p<0.05\right)$. Result illustrates that $30 \%$ girls aged $14-16$ years dropped out from school while this figure was significantly higher among the older adolescents aged 17-18 years (53.6\%). Among the adolescent girls, about half of them belonging to SC (48\%) and ST $(47 \%)$ dropped out followed by girls belonging to other caste (35\%). Higher percentages of girls living in BPL or below BPL family were not in school (45\%) than those belonging to non-BPL families (37\%). Higher percentage (50\%) of dropout was found if girls belonged to family having income from irregular work or labour. Further, if the decision of girls' education was taken by her father, then around $42 \%$ of girls dropped out, while this number reduced significantly when the decision making was joint between a girl and her both parents (36.5\%). However, it was found that if the decision about girls' education was taken by someone else in the family, the dropout of girls was reported as high as $61 \%\left(\chi^{2}, p<0.001\right)$. The data also suggest that parents' education was significantly associated with girls' schooling $\left(\chi^{2}, p<0.001\right)$; three in five girls dropped out among adolescents when both their parents were illiterate, while only one in four among girls reported out of school when both their parents were literate. The results also suggested that the girls who scored low to moderate in the GEM scale, almost $68 \%$ of girls reported school dropout, while the girls who scored high on GEMS, also reported fewer dropout (29\%) (Table 1).

Community-level risk factors like percentage of ST population and percentage of BPL population of village showed significant negative association with dropout; and village mean age at marriage was positively related $(p<0.05)$ while proportion of female literacy of village was significantly linked with school dropout of girl ( $t$-test, $p<0.001)$ (Table 1$)$.

3.3. Adjusted Predictors for School Dropout. Three binary logistic regression models were used to explain girls' school dropout. Pseudo R-square showed that about $26 \%$ of the variation in the adolescent dropouts was explained by full logistic model. To examine if the data and variables selected for the logistic regression was fit for the model, Hosmer-Lemeshow goodness-of-fit test was conducted, which tells us how closely the observed and predicted probabilities match [43]. The statistic $\chi_{\text {HL }}^{2}$ has a larger value, and hence a nonsignificant chi-square $p$ value greater than 0.05 indicated that the data fit the model well (Table 2).

Three separate adjusted models were used to examine the improved model keeping individual and family factors in model 1, followed by adding gender attitude of girls in model 2, and community-level factors in model 3 (Table 3 ). In model 1, the individual and familial factors for example age, number of siblings, her marital situation, and BPL status significantly contributed to the school dropout. The girls who belonged to SC families had significantly higher odds of school dropout $(\mathrm{OR}=1.57, p<0.01)$ compared to non-SC and ST castes (Table 3). Similarly, if the girl belonged to a BPL family, they were $30 \%$ more likelihood of school dropout $(p<0.01)$. The likelihood of dropout significantly increased by $40 \%$ and $11 \%$ with increase in age and number of sibling, respectively $(p<0.001$ and $p<0.01)$. Married girls had significantly higher odds (OR $=1.9, p<0.001)$ of dropouts compared with nonmarried girls, and the likelihood of dropouts was even six times higher $(\mathrm{OR}=5.6, p<0.001)$ when they were staying with their in-laws. In case of families, where either mother or father was educated, the odds of school dropout were $50 \%$ lower $(p<0.001)$ and lowest if both were educated (OR $=0.26, p<0.001)$ compared to illiterate parents. The decision making of parents or family members was not significantly related to girls' school dropout. Similarly, occupation of family was not significantly related to the outcome.

In model 2,gender attitude of girls was included to explain the school dropout of the girl. The result showed that it improved the model by $5 \%$ points (adjusted R-square: 0.2315). Gender perception in adjacent model considerably determined the school dropout. Result stated that girls who scored moderate to higher on Gender Equitable Men Sscale (GEMS) had $50 \%$ to $85 \%$ less likelihood of dropout $(p<0.001)$ compared to girls who had low gender perception. However, effect of sibling burden on girls' discontinuation from school was weakened after controlling for gender perception. This reflects that gender attitudes extremely determined the school dropouts over number of children in family.

In model 3, community factors were included in the analyses along with other predictors which were used in model 1 and 2 to explain school dropout. The analyses showed that this model was the most improved model $(-2$ log likelihood: -797.644 to -710.387 ) as it explained more variations (adjusted R-squared value improved from model 1 to model 3: 0.18 to 0.26 ) as compared to previous two models in terms of explaining the outcome. The result suggests that the proportion of poor (BPL) population, level of mother literacy, and mean age at marriage in community 
TABle 1: Frequency, percent, and chi-square distribution of selected individual and community variables with school status in rural India.

\begin{tabular}{|c|c|c|c|c|c|c|c|}
\hline \multirow{2}{*}{$\begin{array}{l}\text { Variables } \\
\text { Individual/household factors }\end{array}$} & \multirow[b]{2}{*}{ Category } & \multirow[b]{2}{*}{ Percent } & \multicolumn{2}{|c|}{ School status } & \multirow{2}{*}{$\begin{array}{l}\text { Pearson } \\
\text { chi- } \\
\text { squared }\end{array}$} & \multirow[b]{2}{*}{$p$ value } & \multirow[b]{2}{*}{$N$} \\
\hline & & & $\begin{array}{l}\text { Dropout } \\
(\%)\end{array}$ & $\begin{array}{c}\text { In school } \\
(\%)\end{array}$ & & & \\
\hline \multirow{2}{*}{ Current age (years) } & $14-16$ & 52.6 & 30.1 & 69.8 & 82.23 & 0.000 & 760 \\
\hline & $17-18$ & 47.4 & 53.6 & 46.3 & & & 686 \\
\hline \multirow{2}{*}{ Number of siblings } & $0-2$ & 26.0 & 36.7 & 63.3 & 5.48 & 0.019 & 376 \\
\hline & 3 and more & 74.0 & 42.9 & 57.1 & & & 1,070 \\
\hline \multirow{3}{*}{ Caste } & Scheduled caste & 20.5 & 48.3 & 51.7 & 21.51 & 0.011 & 296 \\
\hline & Scheduled tribe & 28.9 & 46.7 & 53.4 & & & 418 \\
\hline & Others & 50.6 & 35.4 & 64.6 & & & 732 \\
\hline \multirow{2}{*}{ Economic status } & BPL family & 54.6 & 44.9 & 55.1 & 9.57 & 0.000 & 790 \\
\hline & Non-BPL family & 45.4 & 36.9 & 63.1 & & & 656 \\
\hline \multirow{3}{*}{ Marital status } & Not married & 73.6 & 32.3 & 67.7 & 164.33 & 0.000 & 1,064 \\
\hline & Married-no Gauna & 13.8 & 52.8 & 47.2 & & & 199 \\
\hline & Married-Gauna performed & 12.6 & 80.9 & 19.1 & & & 183 \\
\hline \multirow{3}{*}{$\begin{array}{l}\text { Occupation of main } \\
\text { earner in family }\end{array}$} & Irregular worker & 45.0 & 49.7 & 50.3 & 38.39 & 0.000 & 650 \\
\hline & Farmer & 47.5 & 35.8 & 64.2 & & & 687 \\
\hline & Formal sector & 7.5 & 25.7 & 74.3 & & & 109 \\
\hline \multirow{3}{*}{ Decision on education } & Father & 55.5 & 42.3 & 57.7 & 21.85 & 0.000 & 803 \\
\hline & Parents and self & 38.1 & 36.5 & 63.5 & & & 551 \\
\hline & Other than parents & 6.4 & 60.9 & 39.1 & & & 92 \\
\hline \multirow{3}{*}{ Parents education } & Both illiterate & 34.9 & 58.8 & 41.2 & 121.10 & 0.000 & 505 \\
\hline & Any parent educated & 35.8 & 38.8 & 61.2 & & & 518 \\
\hline & Both educated & 29.2 & 23.4 & 76.6 & & & 423 \\
\hline \multirow{3}{*}{ Gender perception index } & Low & 17.63 & 67.45 & 32.55 & 143.55 & 0.000 & 255 \\
\hline & Moderate & 23.37 & 52.66 & 47.34 & & & 338 \\
\hline & High & 58.99 & 28.96 & 71.04 & & & 853 \\
\hline Village/community factors & & Mean & & & t-test & $\mathrm{p}$ value & \\
\hline SC and ST population & $\%$ & 28.9 & & & -3.0555 & 0.0011 & 1446 \\
\hline BPL and below BPL & $\%$ & 54.6 & & & -2.2759 & 0.0115 & 1446 \\
\hline Mean age at marriage (years) & & 14.6 & & & 16.76 & 0.0127 & 1446 \\
\hline Mother literacy & $\%$ & 31.8 & & & 8.996 & 0.0000 & 1446 \\
\hline
\end{tabular}

Note. BPL: identified household grouped as poor based on having below poverty line card identified by Government of India.

TABLE 2: Model fitting and amount of variation explained by the model $(N=1446)$.

\begin{tabular}{lccc}
\hline$-2 \log$ likelihood & Pseudo $R^{2}$ & $\begin{array}{c}\text { Hosmer-Lemeshow } \\
\left.\operatorname{chi}^{2} \text { (8 degrees of freedom }\right)\end{array}$ & $p>z$ \\
\hline-710.38721 & 0.2573 & 10.70 & 0.2192 \\
\hline
\end{tabular}

are strong predictors for girls' dropout in the village. Higher poverty level of community significantly (OR: 2.57, $p<0.018$ ) increases the likelihood of dropout by two and half fold. Similarly; every unit increase in mean age at marriage and mothers' literacy rate in the village reduces odds of school dropout significantly by $15 \%(p<0.01)$ and $70 \%$, respectively $(p<0.001)$.

\section{Discussion}

The study highlighted the impact of aggregated community effects on school dropouts of girls residing in rural settings. In extended community interlink model, results demonstrated that girls living in communities with a higher proportion of literate women have lower probability to discontinue school education when controlled for parental and other individual factors. It reflects parents of girl living in communities with educated women may have become aware of advantages of girls' schooling. Therefore, there is a possibility that mothers who has no education, living among educated mothers, have an increased likelihood of passing educational desires to their daughter similar to the educated mothers. Also, girls residing in economically poor community were more likely to dropout from school while adjusted for other factors. These findings are consistent with other studies which highlighted that individual educational outcomes were associated with community education, neighbourhood poverty, and ethnic groups [44].

Results also suggest that family factors, for example, both parents' education was contributing factor for schooling of girls. The likelihood of school dropout was greater for girls having noneducated parents than those who had both the parents educated in the study districts. It has been pointed out in previous studies that parents' education is most critical for child education and their development $[23,24,45,46]$. Most of the girls from the study area perceived that decision on education should be taken by 
TABLE 3: Odds ratio (OR) of school dropouts by selected individual- and community-level predictors.

\begin{tabular}{|c|c|c|c|c|c|c|c|}
\hline \multirow[b]{2}{*}{ Individual/household variables } & \multirow[b]{2}{*}{ Category } & \multicolumn{2}{|c|}{ Model 1} & \multicolumn{2}{|c|}{ Model 2} & \multicolumn{2}{|c|}{ Model 3} \\
\hline & & OR & $p>z$ & OR & $p>z$ & OR & $p>z$ \\
\hline Age (years) & & 1.4 & 0.000 & 1.41 & 0.000 & 1.46 & 0.000 \\
\hline Number of siblings & & 1.11 & 0.008 & 1.07 & 0.062 & 1.06 & 0.178 \\
\hline \multirow{3}{*}{ Caste } & Others $^{@}$ & & & & & & \\
\hline & SC & 1.57 & 0.005 & 1.67 & 0.002 & 1.58 & 0.008 \\
\hline & ST & 1.2 & 0.178 & 1.04 & 0.796 & 1.05 & 0.661 \\
\hline \multirow{2}{*}{ Economic status } & BPL family ${ }^{@}$ & & & & & & \\
\hline & $\begin{array}{l}\text { Non-BPL family } \\
\text { Nonmarried }^{@}\end{array}$ & 0.68 & 0.003 & 0.69 & 0.005 & 0.71 & 0.009 \\
\hline \multirow{2}{*}{ Marital status } & Married-no Gauna & 1.93 & 0.000 & 1.92 & 0.000 & 2.09 & 0.000 \\
\hline & Married-Gauna performed & 5.64 & 0.000 & 5.9 & 0.000 & 6.54 & 0.000 \\
\hline \multirow{3}{*}{ Main occupation of family } & Formal sector $^{@}$ & & & & & & \\
\hline & Irregular worker & 1.86 & 0.015 & 1.45 & 0.177 & 1.38 & 0.255 \\
\hline & Farmer & 1.07 & 0.669 & 1.02 & 0.936 & 1.01 & 0.983 \\
\hline \multirow{3}{*}{ Decision on education taken by } & Only father ${ }^{@}$ & & & & & & \\
\hline & Both parents and self & 0.73 & 0.016 & 0.9 & 0.486 & 0.94 & 0.704 \\
\hline & Other than parents & 1.01 & 0.996 & 0.96 & 0.885 & 0.93 & 0.804 \\
\hline \multirow{3}{*}{ Parents education } & Both illiterate ${ }^{@}$ & & & & & & \\
\hline & Any parent educated & 0.5 & 0.000 & 0.5 & 0.000 & 0.49 & 0.000 \\
\hline & Both educated & 0.26 & 0.000 & 0.27 & 0.000 & 0.3 & 0.000 \\
\hline \multirow{3}{*}{ Gender perception } & Low $^{@}$ & & & & & & \\
\hline & Moderate & & & 0.49 & 0.000 & 0.53 & 0.008 \\
\hline & High & & & 0.16 & 0.000 & 0.18 & 0.000 \\
\hline \multicolumn{8}{|l|}{ Village/environmental variables } \\
\hline$\%$ SC and ST population & & & & & & 0.48 & 0.038 \\
\hline$\%$ BPL population & & & & & & 2.57 & 0.018 \\
\hline Mean age at marriage & & & & & & 0.85 & 0.008 \\
\hline$\%$ mother literacy & & & & & & 0.29 & 0.001 \\
\hline Constant & & 0.003 & 0.000 & 0.08 & 0.000 & 0.14 & 0.009 \\
\hline Adjusted $R^{2}$ & & \multicolumn{2}{|c|}{0.186} & \multicolumn{2}{|c|}{0.2315} & \multicolumn{2}{|c|}{0.2573} \\
\hline$-2 \log$ likelihood & & \multicolumn{2}{|c|}{-797.644} & \multicolumn{2}{|c|}{-753.327} & \multicolumn{2}{|c|}{-710.387} \\
\hline
\end{tabular}

Note. Results control for other covariates of number of siblings, main occupation in family, and decision on education. ${ }^{\circledR}$ Reference category.

a male member or by elders in the family, since they perceive that they are not equal to boys. That redirected gender inequality in school enrolment even after implementation of RTE act, 2010. Average difference between enrolment levels of boys and girls at age 14 declined, but gender difference in enrolment still existed $(32 \%$ girls are not enrolled-compared to $28 \%$ boys). A bridging mechanism for out-of-school children exists at the elementary stage, but are absent for secondary education [47].

Gender inequitable norms prevent girls from making her own decisions even on matter most intrinsic to her living and limit girls' opportunities to form strong social networks, acquire requisite skills, and negotiate with parents for higher education $[48,49]$. Due to restricted mobility, the exposure of girl is limited, and they have low negotiation skills which contribute to school dropout as well.

The gender equitable composite scale clearly demonstrated that gender perception towards equity reduced the dropout rate by $50-80$ percent compared to least equitable gender perception in study districts. These findings corroborate with previous studies that adolescent girls are more likely to have school dropouts due to inequitable gender attitudes [37, 49, 50].
4.1. Study Limitations. This study is restricted to sociodemographically poor districts, and sample data are associated with girls, information; hence, the findings may not be generalized across entire geographic contexts. Also, the use of cross-sectional data limits our ability to make causal inferences. However, study findings highlighted that the better-off community improves in-school status of adolescent girls and also individual gender attitudes enhance equitable acceptance of education of girls. Overall, this study contributes to diffusion of social behaviour theory that community factors may have an impact on family attitude towards value of female education. This study provides opportunity for future research to extend and validate this analysis by including larger representative samples at macrolevel. Further, the research can also look at community wellbeing measures such as population with higher education and nearest city/town from village.

\section{Conclusions}

This study clearly reflects on how community-level factors affect girls' educational attainment. A family living in an educated community may turn out to be aware of 
significance of education and enhance girls' schooling in rural areas. Results highlighted that girls having higher gender perception towards equity are less likely to discontinue from school. Findings from our study confirm that in addition to gender perception and other familial factors, girls belonging to village with lower female literacy were at lower risk of school dropout. The findings are relevant to design and tailor appropriate community-based interventions for addressing school dropout among girls in similar sociocultural settings at the district level with wide spread practice of child marriage and lower female literacy.

Studies have found that the main barriers to educational access and retention at policy and system level in many countries are weakly enforced policies and legislation on access to school for girls and young mother. Further, there is no proper mechanism to tackle and address gender-based violence in the school and other harmful gender-based practices. There is urgent need for out of box thinking and proactive government actions to implement these issues. Community too needs to be sensitized and mobilised to abandon harmful practices.

An intergenerational effect of higher literacy in community may result faster development than lower educated community even from same investment for current educational attainment of present cohorts. A thorough investigation into the ways in which household and community education affects school attendance may be useful in helping to guide future investments and policy interventions which aim to stimulate demand for female education should be made. One recommendation from this study is that, given the significance of the diffusion of educational advantage at the community level, future policies may seek to develop community-based programmes to increase awareness of at least primary education as well as promote continuing at this educational level. Study clearly emphasises the need for government policy to promote mother's education up to higher education level, promoting participation of women in household decision making within family. These factors, if addressed effectively, can have a lasting effect on women's further education and also in lowering children's school dropout in rural India.

\section{Appendix}

\section{A. Gender Equitable Men Scale (GEMS)}

The measure of GEM scale was adopted in Pulerwitz and Barker [38] study. This scale consisted of 35 statements which covered broad domain on gender norms, education, reproductive rights, autonomy and empowerment, family planning, and so on. Three degrees of perceived attitude was coded on the scale as 0 to 2 as disagree to agree based on their equitable direction (positive or negative). A score of 0 was given to the most negative statement, and a score of 2 was assigned to the most positive statement, while the score of 1 was assigned when the respondent said "somewhat agree" to a particular statement. Internal consistency and reliability analyses were conducted by calculating Cronbach's alpha.
TABLE 4: Description of items in GEMS scale.

\section{Items in scale}

A woman's most important role is to take care of her home and cook for her family

2 Girls can go to school even if it is far away from her village

3 Boys are naturally better than girls in studies

4 It is more important to educate boys than to educate girls

5 Since girls have to get married, they should not be sent to schools for higher education

For an ideal Indian woman, family and house hold work are more important than education.

7 Investing in girls education is not financially beneficial

8 It is not safe to send girls to school due to violence

9 Eighteen years is too late for a girl to get married

10 Marrying girls early helps to protect them from sexual relations

11 A girl who is not married young is a risk to her family

12 Girls should be allowed to take decisions regarding their marriage

13 Girls are ready for marriage after first menstruation

14 A girl must get married when she finds an appropriate groom, even if she was still studying in school

Girls and boys should keep their parents/elders happy even if they have to marry early

16 Having a daughter is a financial burden

17 It is unsafe to send girls to school after the onset of menstruation (MC)

18 A girl should not have sex before marriage

19 Men should share the work around the house with women such as doing dishes, cleaning, and cooking

20 Early child bearing makes women valuable in family and society

21 A man should only have the final say in all family matters Items dropped from the scale after principal component analysis

1 Girls can walk safely in areas were men and boys usually gather

2 A man has the right to have sex even if the woman says no

3 A woman should obey her husband

4 Women/girls should tolerate violence in order to keep her family together

5 It is a woman's responsibility to avoid getting pregnant

6 Decision to plan a family should be taken jointly by husband and wife

7 A woman can suggest using contraceptives just like a man can

8 A woman has the right to use contraceptives, even if her husband does not agree.

9 A woman should be able to say no to have sex if she does not want it.

I would feel ashamed to talk about contraceptives to my husband.

11 Only men can decide when to have a first child

12 If a couple does not have a child, then it is a woman's fault It is the man who should decide whether to use a contraceptives or not

Woman should conceive within one year of marriage to

14 avoid society/community pressure/ridicule

\section{Data Availability}

Data were owned by donor agency (American Jewish World Service, US) and program implementation institute (MAMTA Health Institute for Mother and Child, India). The authors are only authorized to explore the possibility on some research issues/gaps to be focused/addressed on; hence, data may not be made available in the public domain 
due to ethical concerns. However, they may be shared only with editors/reviewers on request if required.

\section{Disclosure}

The funding source had no involvement in analysis or interpretation of data, or the decision to submit the article for publication.

\section{Conflicts of Interest}

The authors in this study declare no conflicts of interest.

\section{Conflicts of Interest}

The authors in this study declare no conflicts of interest.

\section{Acknowledgments}

This baseline study, part of an intervention research program, is an effort of MAMTA Health Institute for Mother and Child to promote education and delay marriage of adolescents towards their impending wellbeing. The authors truly acknowledge the support received from several colleagues through the course of the study-Praveer Goel, for his state co-ordination during data collection, and Surendra K. Mishra, for his contribution in setting up the study and overall program management support. The study was a part of proposed intervention-based project, which was financially supported by American Jewish World Service (AJWS) for the survey and instrumentation.

\section{References}

[1] Ministry of Human Resource Development (MHRD), Annual Report 2013-2014, Government of India, New Delhi, India, 2015, http://mhrd.gov.in/sites/upload_files/mhrd/files/ document-reports/AR2013-14.pdf.

[2] NUEPA, Secondary Education in India: Progress towards Universalisation, Unified District Information System of Education 2013-14, NUEPA, New Delhi, India, 2014.

[3] Save the Children: WINGS 2014-The Worlds of India's Girls, Save the children, New Delhi, India, 2014, http://resourcecentre. savethechildren.se/sites/default/files/documents/executive_ summary_of_wings_2014.pdf.

[4] UNDP, Human Development Report 2010: The Real Wealth of Nations: Pathways to Human Development, UNDP, New York, NY, USA, 2010, http://hdr.undp.org/sites/default/files/ reports/270/hdr_2010_en_complete_reprint.pdf.

[5] F. N. Chege and D. N. Sifuna, Girls' and Women's Education in Kenya: Gender Perspectives and Trends, UNESCO, Paris, France, 2006.

[6] S. Verick, "Female labor force participation in developing countries," IZA World of Labor, vol. 87, 2014.

[7] R. N. Prakash, T. S. Beattie, P. Javalkar et al., "Correlates of school dropout and absenteeism among adolescent girls from marginalized community in north Karnataka, south India," Journal of Adolescence, vol. 61, pp. 64-76, 2017.

[8] A. M. R. Chowdhury, S. R. Nath, R. K. Choudhury, and M. Ahmed, Renewed Hope Daunting Challenges, Campaign for Popular Education and University Press Limited, Dhaka, Bangladesh, 2002.
[9] P. H. Brown and A. Park, "Education and poverty in rural China," Economics of Education Review, vol. 21, no. 6, pp. 523-541, 2002.

[10] S. Battin-Pearson, M. D. Newcomb, R. D. Abbott, K. G. Hill, R. F. Catalano, and J. D. Hawkins, "Predictors of early high school dropout: a test of five theories," Journal of Educational Psychology, vol. 92, no. 3, pp. 568-582, 2000.

[11] M. J. Grant and K. K. Hallman, "Pregnancy-related school dropout and prior school performance in KwaZulu-Natal, South Africa," Studies in Family Planning, vol. 39, no. 4, pp. 369-382, 2008.

[12] N. Farah and M. P. Upadhyay, "How are school dropouts related to household characteristics? Analysis of survey data from Bangladesh," Cogent Economics and Finance, vol. 5, no. 1, article 1268746, 2017.

[13] R. J. Sampson, "The neighborhood context of investing in children: Facilitating mechanisms and undermining risks," in Securing the Future for Children, J. W. Danziger, Ed., pp. 205-227, Russell Sage Foundation, New York, NY, USA, 2000.

[14] R. J. Sampson, J. D. Morenoff, and T. Gannon-Rowley, "Assessing "Neighborhood Effects": social processes and new directions in research," Annual Review of Sociology, vol. 28, no. 1, pp. 443-478, 2002.

[15] G. C. Galster, "Quantifying the effect of neighbourhood on individuals: challenges, alternative approaches, and promising directions," Schmollers Jahrbuch, vol. 128, no. 1, pp. 7-48, 2008.

[16] V. Dupere, T. Leventhal, R. Crosnoe, and E. Dion, "Understanding the positive role of neighborhood socioeconomic advantage in achievement: the contribution of the home, child care, and school environments," Developmental Psychology, vol. 46, no. 5, pp. 1227-1244, 2010.

[17] M. Van Ham, D. Manley, N. Bailey, L. Simpson, and D. Maclennan, "Neighbourhood effects research: new perspectives," in Neighbourhood Effects Research: New Perspectives, pp. 1-21, Springer, Dordrecht, Netherlands, 2012.

[18] J. Brooks-Gunn, G. J. Duncan, P. K. Klebanov, and N. Sealand, "Do neighborhoods influence child and adolescent development?," American Journal of Sociology, vol. 99, no. 2, pp. 353-395, 1993.

[19] M. M. Criss, D. S. Shaw, K. L. Moilanen, J. E. Hitchings, and E. M. Ingoldsby, "Family, neighborhood, and peer characteristics as predictors of child adjustment: a longitudinal analysis of additive and mediation models," Social Development, vol. 18, no. 3, pp. 511-535, 2009.

[20] T. Leventhal, V. Dupéré, and J. Brooks-Gunn, Neighborhood Influences on Adolescent Development: Handbook of Adolescent Psychology, John Wiley \& Sons, Hoboken, NJ, USA, 2009.

[21] N. Sastry and A. R. Pebley, "Family and neighborhood sources of socioeconomic inequality in children's achievement," Demography, vol. 47, no. 3, pp. 777-800, 2010.

[22] S. Anderson, T. Leventhal, and V. Dupéré, "Exposure to neighborhood affluence and poverty in childhood and adolescence and academic achievement and behavior," Applied Developmental Science, vol. 18, no. 3, pp. 123-138, 2014.

[23] Y. Xue, T. Leventhal, J. Brooks-Gunn, and F. J. Earls, "Neighborhood residence and mental health problems of 5- to 11-year-olds," Archives of General Psychiatry, vol. 62, no. 5, pp. 554-563, 2005.

[24] P. Glick and D. E. Sahn, "Schooling of girls and boys in a West African country: the effects of parental education, income, and household structure," Economics of Education Review, vol. 19, no. 1, pp. 63-87, 2000. 
[25] A. Latif, A. I. Choudhary, and A. A. Hammayun, "Economic effects of student dropouts: a comparative study," Journal of Global Economics, vol. 3, no. 137, 2015.

[26] S. M. Shahidul, "Household decision-making process: it's effect on school dropout behavior for girls in the secondary school level in Bangladesh," International Education Studies, vol. 6 , no. 1, p. 132, 2012.

[27] International Institute for Population Sciences, District Level Household and Facility Survey (DLHS-3), 2007-08, IIPS, Mumbai, India, 2010.

[28] M. G. Hickey and M. Stratton, "Schooling in India: effects of gender and caste," Scholarlypartnershipsedu, vol. 2, no. 1, p. 6, 2007.

[29] S. L. Pong, J. Dronkers, and G. Hampden-Thompson, "Family policies and children's school achievement in single-versus two-parent families," Journal of Marriage and Family, vol. 65, no. 3, pp. 681-699, 2003.

[30] S. M. Gouda and T. V. Sekher, "Factors leading to school dropouts in India: an analysis of national family health survey-3 data," International Journal of Research and Method in Education, vol. 4, no. 6, pp. 75-83, 2014.

[31] S. Amjad, Out-of-School Girls: Challenges and Policy Responses in Girls' Education in Tajikistan, UNICEF, New York, NY, USA, 2016, http://www.unicef.org/ceecis/girls_ tajik.pdf.

[32] W. Simon, J. Gagnon, R. Parker, and P. Aggleton, "Culture, society and sexuality: a reader," in Culture, Society and Sexuality: A Reader, Routledge, London, UK, 1999.

[33] R. Verma, Girl Child and Family Development in Indian Society, Anamika Publishers, New Delhi, India, 2000.

[34] K. D. Gangrade, Crisis of Values: A Study in Generation Gap, Chetana Publications, Mumbai, India, 1975.

[35] D. Sarada, Family Life Education for Adolescent Girls, Discovery Publishing House, New Delhi, India, 1999.

[36] M. C. M. Leung and J. Zhang, "Gender preference, biased sex ratio, and parental investments in children in single-child households," Review of Economics of the Household, vol. 6, no. 2, pp. 91-110, 2008.

[37] P. Achyut, N. Bhatla, S. Khandekar, S. Maitra, and R. K. Verma, Building Support for Gender Equality among Young Adolescents in School: Findings from Mumbai, India, ICRW, New Delhi, India, 2011.

[38] J. Pulerwitz and G Barker, "Measuring attitudes toward gender norms among young men in Brazil development and psychometric," Evaluation of the GEM Scale Men and Masculinities, vol. 10, no. 3, pp. 322-338, 2008.

[39] H. F. Kaiser, "The application of electronic computers to factor analysis," Educational and Psychological Measurement, vol. 20, no. 1, pp. 141-151, 1960.

[40] R. B. Cattell, "The Scree test for the number of factors," Multivariate Behavioral Research, vol. 1, no. 2, pp. 245-276, 1966.

[41] J. C. Nunnally and I. H. Bernstein, Psychometric Theory, McGraw-Hill, New York, NY, USA, 3rd edition, 1994.

[42] P. D. Allison, "Comparing logit and probit coefficients across groups," Sociological Methods and Research, vol. 28, no. 2, pp. 186-208, 1999.

[43] D. W. Hosmer and S. Lemeshow, Applied Logistic Regression, S. S. W. Walter and A. Shewhart, Eds., John Wiley and Sons, Hoboken, NJ, USA, 2nd edition, 2005.

[44] J. Nieuwenhuis and P. Hooimeijer, "The association between neighbourhoods and educational achievement, a systematic review and meta-analysis," Journal of Housing and the Built Environment, vol. 31, no. 2, pp. 321-347, 2016.
[45] F. Leclercq, Patterns and Determinants of Elementary School Enrolment in Rural North India, TEAM-CNRS: Universite de Paris 1, Paris, France, 2001.

[46] S. Das and D. Mukherjee, "Role of women in schooling and child labour decision: the case of urban boys in India," Social Indicators Research, vol. 82, no. 3, pp. 463-486, 2007.

[47] ASER, Annual Status of Education Report 2017 'Beyond Basics' (Rural), ASER, New Delhi, India, 2018, http://img. asercentre.org/docs/Publications/ASER\%20Reports/ASER\% 202017/aser2017fullreportfinal.pdf.

[48] International Center for Research on Women and Engender Health, Youth Reproductive Health in Nepal: Is Participation the Answer? 1998-2003, EngenderHealth, Washington, DC, USA, 2003.

[49] Indian Institute for Health Management and Research, End Line Evaluation Report of EU Supported Increasing Age at Marriage to Improve Sexual and Reproductive Health of Young People 2009-13, IIHMR, Kolkata, India, 2013.

[50] G. Barker, J. M. Contreras, B. Heilman, A. K. Singh, R. K. Verma, and M. Nascimento, Evolving Men: Initial Results from the International Men and Gender Equality Survey (IMAGES), International Center for Research on Women (ICRW) and Rio de Janeiro: Instituto Promundo, Washington, DC, USA, 2010. 


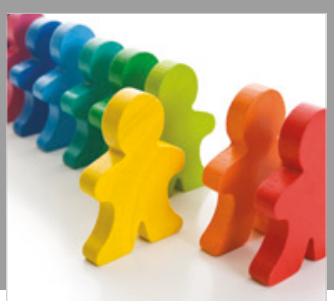

Autism

Research and Treatment
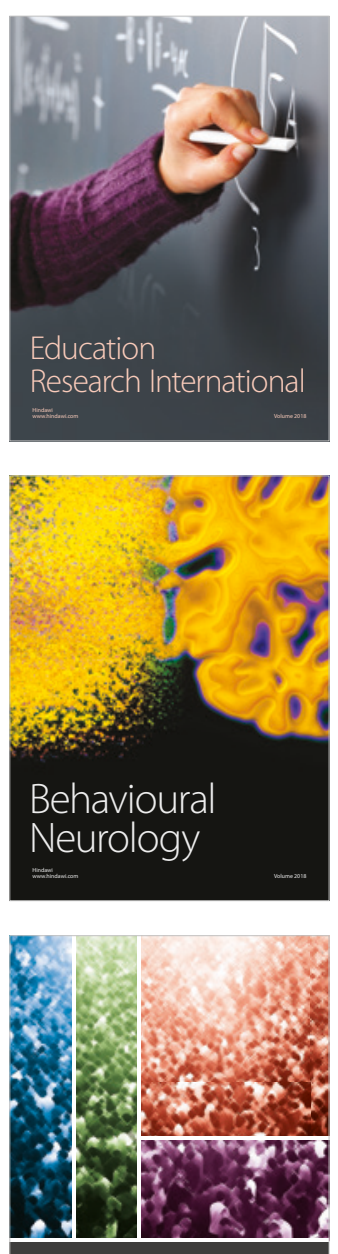

International Journal of

Population Research

$\underline{-m}$

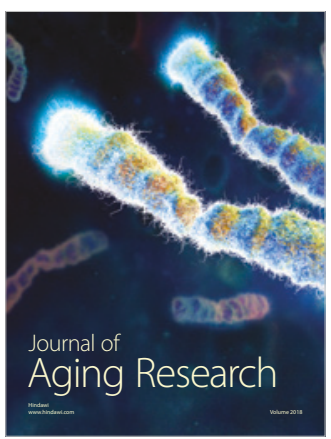

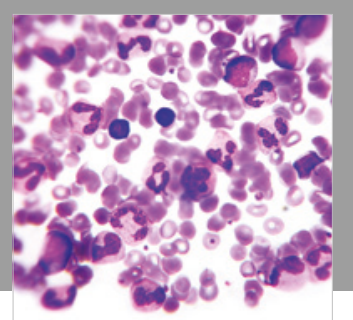

Pathology

Research International$$
=
$$

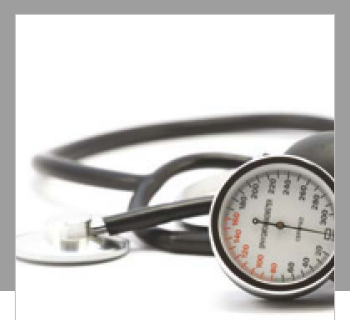

Nursing

Research and Practice

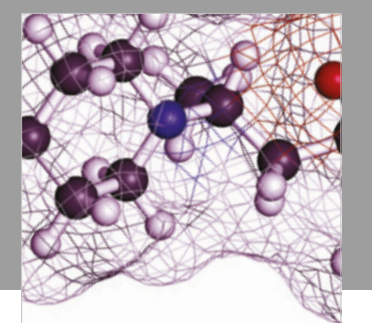

Pain

Research and Management

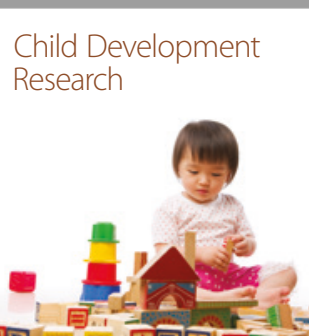

बाD

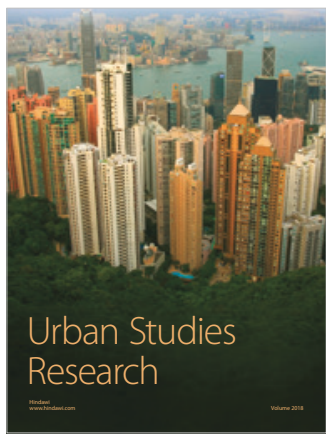

\section{Hindawi}

Submit your manuscripts at

www.hindawi.com
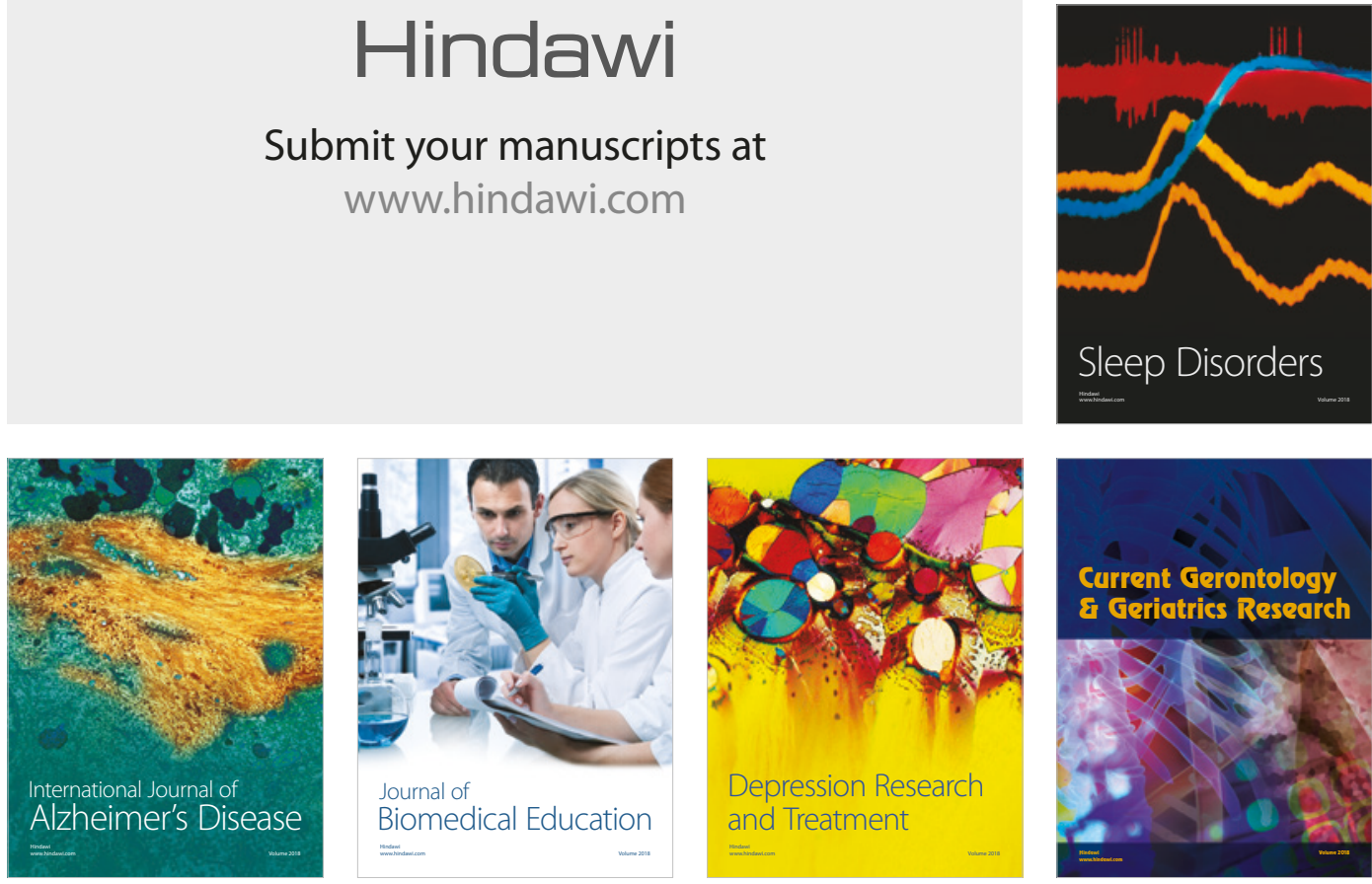

Journal of

Biomedical Education

$=$

smman

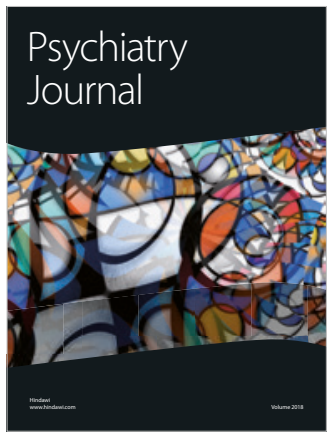

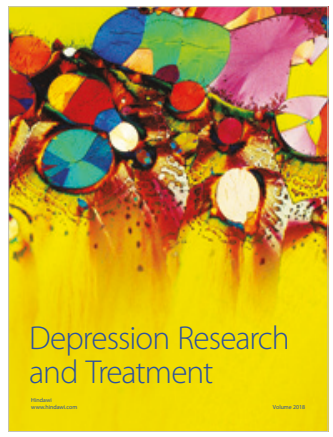
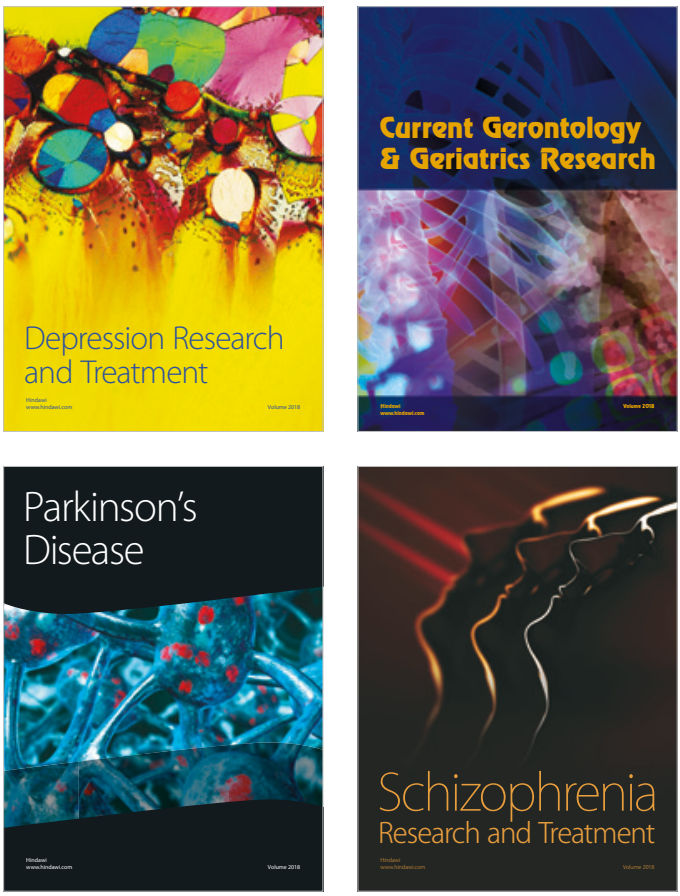